\title{
Tamoxifen enhances the cytotoxic effects of nelfinavir in breast cancer cells
}

\author{
Ansgar Brüning ${ }^{* 1,2}$, Klaus Friese ${ }^{1,2}$, Alexander Burges ${ }^{\dagger 2}$ and loannis Mylonas ${ }^{\dagger 1}$
}

\begin{abstract}
Introduction: The HIV protease inhibitor nelfinavir is currently under investigation as a new anti-cancer drug. Several studies have shown that nelfinavir induces cell cycle arrest, endoplasmic reticulum stress, autophagy, and apoptosis in cancer cells. In the present article, the effect of nelfinavir on human breast cancer cells is examined and potential combination treatments are investigated.

Methods: The effects of nelfinavir and tamoxifen on the human breast cancer cell lines MCF7, T47 D, MDA-MB-453, and MDA-MB-435 were tested by analysing their influence on cell viability (via 3-(4,5-dimethylthiazol-2-yl)-2,5-

diphenyltetrazolium bromide assay), apoptosis (annexin binding, poly(ADP-ribose) polymerase cleavage), autophagy (autophagy marker light chain 3B expression), endoplasmic reticulum stress (binding protein and activating transcription factor 3 expression), and the occurrence of oxidative stress (intracellular glutathione level).

Results: Nelfinavir induced apoptosis in all four breast cancer cell lines tested, although the extent of autophagy and endoplasmic reticulum stress varied among the cell lines. The concentration of nelfinavir needed for an efficient induction of apoptosis in breast cancer cells could be reduced from $15 \mu \mathrm{g} / \mathrm{ml}$ to $6 \mu \mathrm{g} / \mathrm{ml}$ when combined with tamoxifen. At a concentration of $6 \mu \mathrm{g} / \mathrm{ml}$, tamoxifen substantially enhanced the endoplasmic reticulum stress reaction in those cell lines that responded to nelfinavir with binding protein (BiP) upregulation (MCF7, T47D), and enhanced autophagy in cell lines that responded to nelfinavir treatment with autophagy marker light chain 3B upregulation (MDA-MB-453). Although tamoxifen has been described to be able to induce oxidative stress at concentrations similar to those applied in this study $(6 \mu \mathrm{g} / \mathrm{ml})$, we observed that nelfinavir but not tamoxifen reduced the intracellular glutathione level of breast cancer cells within hours of application by up to $32 \%$, suggesting the induction of oxidative stress was an early event and an additional cause of the apoptosis induced by nelfinavir.

Conclusions: The results demonstrate that nelfinavir may be an effective drug against breast cancer and could be combined with tamoxifen to enhance its efficacy against breast cancer cells. Moreover, the cytotoxic effect of a tamoxifen and nelfinavir combination was independent of the oestrogen receptor status of the analysed breast cancer cells, suggesting a potential benefit of a combination of these two drugs even in patients with no hormone-responsive tumours. We therefore recommend that clinical studies on nelfinavir with breast cancer patients should include this drug combination to analyse the therapeutic efficacy as well as the safety and tolerability of this potential treatment option.
\end{abstract}

\section{Introduction}

Breast cancer is the most frequent cancer in the female population [1]. Although tremendous progress in the treatment of breast cancer has been achieved during past

\footnotetext{
* Correspondence: ansgar.bruening@med.uni-muenchen.de

1 Department of Obstetrics and Gynaecology, Campus Innenstadt, Ludwig-

Maximilians-University Munich, 11 Maistrasse, Munich 80337, Germany

+ Contributed equally

Full list of author information is available at the end of the article
}

decades, it is still the principal cause of cancer death for females worldwide [1,2].

Tamoxifen is a selective oestrogen receptor antagonist, and since its introduction in cancer therapy has become the standard treatment option for hormone-responsive breast cancer patients [2-5]. Not all breast cancer patients, however, benefit from an endocrine therapy with tamoxifen [3]. Interestingly, several hormone receptor-independent effects of tamoxifen have been described, leading to apoptosis when higher concentra- 
tions of tamoxifen are applied [6,7]. A combination therapy of tamoxifen with other drugs that cause synergistic anti-tumour effects might therefore be an interesting option in the therapy of breast carcinomas.

Nelfinavir (Viracept; Pfizer, Groton, CT, USA) is an HIV protease inhibitor that has long been an essential component of the antiviral combination highly active antiretroviral therapy. Several recent in vitro studies have indicated that nelfinavir has potential anti-tumoral effects [8,9], and clinical studies on nelfinavir are ongoing to confirm its efficacy against human cancers in vivo [1013]. Nelfinavir exerts pleiotropic effects on cancer cells, including induction of apoptosis, necrosis, and autophagy $[9,14,15]$. Nelfinavir is believed to either cross-react with a protease of the cytoplasmic proteasomal protein degradation machinery or with endoplasmic reticulum-resident proteases $[15,16]$. In both cases, this protease inhibition can lead to the accumulation of misfolded proteins that cause the unfolded protein response or endoplasmic reticulum stress response [17-19]. These pathways are primarily associated with a transient cell cycle arrest and upregulation of molecular chaperones such as binding protein ( $\mathrm{BiP})$ and other members of the heat shock family, in order to repair and prevent further cell damage [18]. A prolonged or irreparable stress reaction, however, eventually switches from a repair and survival mechanism to cell death executed by apoptosis $[20,21]$. This nonclassical cell death mechanism has recently become of interest because of its ability to act even on otherwise chemoresistant human cancer cells $[15,22]$.

Since the orally available drugs tamoxifen and nelfinavir have anti-tumoral properties, a combination of these medications might be an intriguing option in the therapy of breast cancer patients. However, no data regarding their potential synergistic effects are yet available. We therefore tested the effect of nelfinavir and tamoxifen with regard to the influence on apoptosis, endoplasmic reticulum stress, autophagy, and oxidative stress in breast cancer cells with different oestrogen receptor status.

\section{Materials and methods}

\section{Cells and cell culture}

The breast cancer cell lines T47 D (ATCC HTB 133; oestrogen receptor-positive), MCF7 (ATCC HTB 22; oestrogen receptor-positive), MDA-MB-453 (ATCC HTB 131; oestrogen receptor-negative), and MDA-MB-435 S (ATCC HTB 129; oestrogen receptor-negative) - all kindly provided by G Saretzki (Newcastle, UK) - were cultured in RPMI-1640 medium supplemented with 10\% foetal calf serum and antibiotics at $37^{\circ} \mathrm{C}$ in a humidified atmosphere with $5 \% \mathrm{CO}_{2}$. All cell culture reagents were from PAA (Pasching, Austria).

\section{Drugs and drug treatment}

Nelfinavir (Viracept ${ }^{\circ}$ ) was generously provided by Pfizer. Nelfinavir was dissolved in ethanol and kept at $-20^{\circ} \mathrm{C}$ as a $100 \mathrm{mg} / \mathrm{ml}$ stock solution. Tamoxifen (Sigma, Munich, Germany) was dissolved in dimethylsulfoxide at a concentration of $100 \mathrm{mg} / \mathrm{ml}$. In control experiments, equal amounts of dimethylsulfoxide or ethanol were added.

\section{Cell proliferation analysis}

A total of $2 \times 10^{4}$ cells per well were seeded in quadruplicate in 24-well cell culture plates and were incubated with nelfinavir for up to 4 days. The number of viable, trypan blue-excluding cells was determined by a haemocytometer.

\section{MTT assay}

For the 3-(4,5-dimethyl-2-thiazolyl)-2,5-diphenyl-2H-tetrazolium bromide (MTT) assay analysis, $20 \mu \mathrm{l}$ MTT (Sigma) stock solution ( $5 \mathrm{mg} / \mathrm{ml}$ PBS) was added to viable cells in $200 \mu \mathrm{l}$ cell culture medium for 1 hour under cell culture conditions. The water-insoluble precipitate was dissolved in $100 \mu \mathrm{l}$ dimethylsulfoxide and analysed by an ELISA reader at $595 \mathrm{~nm}$.

\section{Annexin binding assay}

FITC-labelled annexin V (Biocat, Heidelberg, Germany) was applied to viable cells as recommended by the supplier in combination with propidium iodide, and was analysed by FACScan with an FL-1 setting (propidium iodide) at $575 \mathrm{~nm}$ and an FL-2 setting (FITC) at $530 \mathrm{~nm}$. FACScan analysis was performed using a Becton Dickinson FACScan analyser (Becton Dickinson, Heidelberg, Germany).

\section{Western blot analysis}

Cell extracts of cancer cells cultured in cell culture plates were prepared with radio-immunoprecipitation buffer (50 mM Tris, pH 8.0, $150 \mathrm{mM} \mathrm{NaCl}, 1 \% \mathrm{NP} 40,0.5 \%$ doxycholine, 0.1\% SDS) and $20 \mu \mathrm{g}$ protein (BioRad Bradford Assay; BioRad, Munich, Germany) were subjected to SDS-PAGE. Proteins were transferred to polyvinylidene fluoride membranes in a BioRad Mini Protean II Cell (BioRad) at $1 \mathrm{~mA} / \mathrm{cm}^{2}$ membrane in $10 \%$ methanol, 192 $\mathrm{mM}$ glycine, $25 \mathrm{mM}$ Tris, $\mathrm{pH}$ 8.2. Membranes were blocked with $4 \%$ nonfat milk powder in PBS-0.05\% Tween for 4 hours. Primary antibodies were applied in blocking buffer and incubated at room temperature overnight.

Antibodies against poly(ADP-ribose) polymerase, phospho-ERK1/2 (pp44/pp42), AKT, phospho-AKT, mcl1 , ІкB, and autophagy marker light chain $3 \mathrm{~B}$ were all purchased from Cell Signaling Technology (NEB, Frankfurt, Germany). Antibodies against BiP (H-129), activating transcription factor $3(\mathrm{C}-19)$ and $\beta$-actin (C4) were from SantaCruz Biotech (Heidelberg, Germany). Secondary, 
alkaline phosphatase-coupled antibodies against the corresponding primary antibodies were from Dianova (Hamburg, Germany). Alkaline phosphatase detection was performed either by the chromogenic BCIP/NBT assay (Promega, Mannheim, Germany) or by the chemiluminescent alkaline phosphatase detection assay (Millipore, Schwalbach, Germany), and the results were analysed and documented using a BioRad QuantityOne Image Analyzer and documentation software (BioRad).

\section{Determination of intracellular glutathione levels}

To detect intracellular glutathione levels, cells were seeded in 96-well cell culture dishes and allowed to grow for 24 hours under cell culture conditions. Cells were then incubated with the cytotoxic drugs for up to 5 hours. Intracellular glutathione levels were quantified using the bioluminescent Promega GSH-Glo ${ }^{\mathrm{Tm}}$ glutathione assay (Promega), essentially as recommended by the supplier. In brief, adherent cells were directly dissolved in $100 \mu \mathrm{l}$ GSH-Glo ${ }^{\mathrm{Tm}}$ lysis and reaction buffer. After addition of 100 $\mu \mathrm{GSH}-\mathrm{Glo}^{\mathrm{m}}$ Luciferin detection reagent, luminescence was detected using a MicroLumat LB 96P bioluminometer (EG\&G Berthold, Bad Wildbad, Germany).

\section{Determination of proteasomal activity}

For the determination of cellular proteasome activity, cells were seeded in 96-well cell culture dishes, allowed to grow for 24 hours under cell culture conditions, and then incubated with cytotoxic drugs for up to 5 hours. Proteasomal activity was analysed using the bioluminescent Promega Proteasome-Glo ${ }^{\mathrm{TM}}$ assay (Promega) as recommended by the supplier. Adherent cells were directly dissolved in $50 \mu \mathrm{l}$ Proteasome-Glo ${ }^{\mathrm{Tm}}$ lysis and reagent buffer, containing Suc-LLVY-aminoluciferin as a substrate. Leukaemia cells were collected by centrifugation before lysis. Bioluminescence was detected using a MicroLumat LB 96P bioluminometer (EG\&G Berthold).

\section{Statistical analysis}

All experiments, except western blots and FACScan analysis, were performed in quadruplicate. The results were evaluated using the nonparametric Wilcoxon sum test and the Mann-Whitney $U$ rank-sum test where applicable (PASW version 17.0; SPSS Inc., Chigaco, IL, USA). Values were plotted as the mean \pm standard deviation, and significance was assumed at $P<0.05$ using the two-tailed test. Significant relations are indicated in the figures and the statistical test used is mentioned in the corresponding figure legend.

\section{Ethical aspects}

All experiments were performed on established cancer cell lines. No ethical approval or informed consent was thus needed.

\section{Results}

Nelfinavir reduces cell proliferation of breast cancer cells and is able to induce apoptosis in breast cancer cells when applied at higher concentrations

The human breast cancer cell lines T47 D, MCF7, MDAMB-453, and MDA-MB-435 were incubated with nelfinavir at various concentrations with various time intervals and were analysed for cell proliferation by counting viable cells. Low doses of nelfinavir $(5 \mu \mathrm{g} / \mathrm{ml})$ reduced the cell proliferation of breast cancer cells, and complete cell death was achieved at a concentration of $15 \mu \mathrm{g} / \mathrm{ml}$ (Figure 1). Nelfinavir acted on oestrogen receptor-positive (T47 $\mathrm{D}, \mathrm{MCF7}$ ) as well as on oestrogen receptor-negative (MDA-MB-453, MDA-MB-435) breast cancer cell lines.

\section{Tamoxifen enhances the cytotoxic effect of nelfinavir}

The mean plasma concentration of nelfinavir in HIVinfected persons taking oral doses of nelfinavir was determined to be $2.2 \mu \mathrm{g} / \mathrm{ml}$, reaching maximal plasma concentrations of up to $4 \mu \mathrm{g} / \mathrm{ml}[23,24]$. These concentrations can achieve only a partial reduction of breast cancer cell proliferation (Figure 1), and are not efficient in inducing apoptosis in breast cancer cells. The plasma concentration of nelfinavir, however, can be significantly increased by administering higher oral doses of nelfinavir or by intravenous application of nelfinavir [25]. Still, a possible combination strategy of nelfinavir with other chemotherapeutic drugs that would allow a reduction of single drug concentrations would be advantageous.

When combining nelfinavir with tamoxifen, we observed a substantially enhanced induction of cell death even at lower nelfinavir concentrations (Figure 2). For example, when used as a single agent, $6 \mu \mathrm{g} / \mathrm{ml}$ nelfinavir induced only a slight and nonsignificant reduction of cell viability by $6.1 \%$ in MCF7 cells and by $6.4 \%$ in T47 D cells (Figure 2). Tamoxifen at $6 \mu \mathrm{g} / \mathrm{ml}$ reduced the cell viability by $26.5 \%$ in MCF7 cells and by $40 \%$ in T47 D cells (Figure $2 ; P<0.05)$. The combination of both nelfinavir and tamoxifen, however, significantly reduced cell viability of MCF7 cells and T47 D cells by up to $77.0 \%$ and $76.8 \%$, respectively (Figure $2 ; P<0.05$ ). FACScan analysis confirmed that the combination of $6 \mu \mathrm{g} / \mathrm{ml}$ nelfinavir with 6 $\mu \mathrm{g} / \mathrm{ml}$ tamoxifen efficiently induced apoptosis in breast cancer cells (Figure 3 and Table 1), although the same concentrations proved to be insufficient for the induction of apoptosis when used as single agents (Figure 3 and Table 1).

\section{Nelfinavir exerts pleiotropic proapoptotic and anti- apoptotic effects in breast cancer cells}

To gain a better insight into the cell death mechanism induced by nelfinavir alone and in combination with tamoxifen, Western blot analyses of drug-treated breast cancer cells were performed. First, the effects of nelfina- 


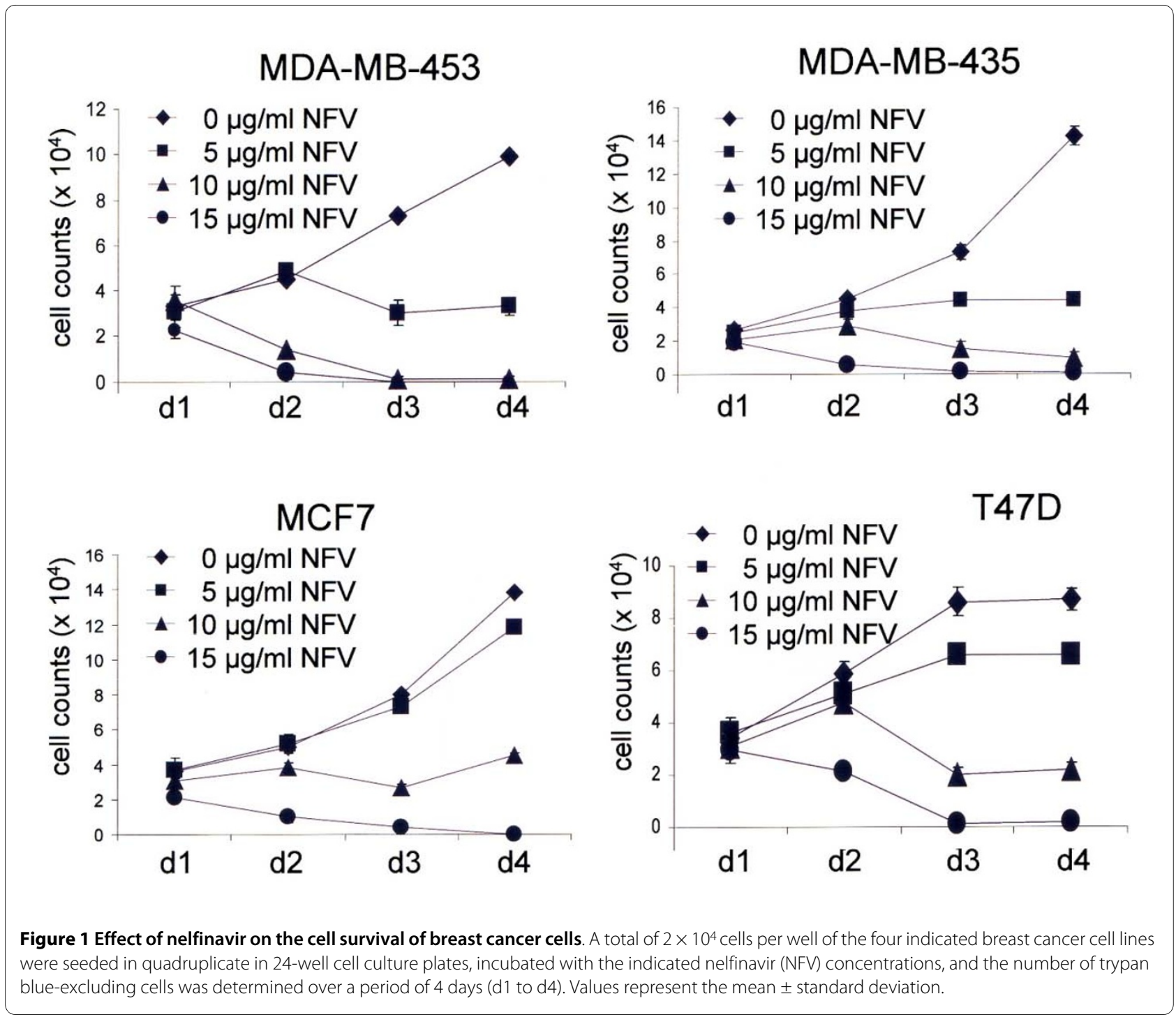

vir as a single agent on breast cancer cells were analysed. Using the cleavage of poly(ADP-ribose) polymerase as an indicator of apoptosis, the specific induction of apoptosis in breast cancer cells by high nelfinavir concentrations $(15 \mu \mathrm{g} / \mathrm{ml})$ could be confirmed (Figure 4). Western blotting further showed upregulation of $\mathrm{BiP}$ and activating transcription factor 3 (ATF3) in nelfinavir-treated breast cancer cells, indicating induction of endoplasmic reticulum stress. Upregulation of $\mathrm{BiP}$ following nelfinavir treatment, however, was scarcely detectable in MDA-MB-453 cells. In these cells, strong upregulation of autophagy marker light chain 3B could be observed instead.

In all four cell lines, no change in the expression of the proteasome-regulated NF- $\mathrm{kB}$ inhibitor $\mathrm{I} \kappa \mathrm{B}$ could be observed, suggesting no influence of nelfinavir on the proteasome activity in breast cancer cells. We have previously described an upregulation of the anti-apoptotic mcl-1 protein by nelfinavir in ovarian cancer cells [26], but this could only be observed in one (MDA-MB-435) of the four tested breast cancer cell lines. Nelfinavir has further been described as reducing AKT phosphorylation, resulting in enhanced radiosensitivity $[11,16]$ - which could be of special importance for breast cancer treatment, for which radiotherapy can be applied. We observed no inhibition of AKT signalling in MCF7 and T47 D cells by nelfinavir, however, and we even observed a markedly enhanced AKT phosphorylation level in nelfinavir-treated MDA-MB-453 and MDA-MB-435 cells (Figure 4).

\section{Tamoxifen enhances the pleiotropic effects of nelfinavir in breast cancer cells}

The effects of tamoxifen on the proapoptotic and antiapoptotic pathways that were induced by nelfinavir (Figure 4) were further investigated. Cell lysates of breast cancer cells treated with $6 \mu \mathrm{g} / \mathrm{ml}$ nelfinavir or $6 \mu \mathrm{g} / \mathrm{ml}$ 
Table 1: Quantitative analysis of apoptotic and necrotic cells after tamoxifen and nelfinavir treatment

\begin{tabular}{lllll}
\hline Cell line & LL (\%) & UL (\%) & UR (\%) & LR (\%) \\
\hline T47D & & & & 0.03 \\
Control & 98.78 & 0.44 & 0.77 & 0.17 \\
TAM 6 $\mu \mathrm{g} / \mathrm{ml}$ & 92.71 & 4.42 & 2.71 & 0.03 \\
NFV 6 $\mu \mathrm{g} / \mathrm{ml}$ & 95.50 & 2.17 & 2.31 & 1.34 \\
TAM/NFV & 11.18 & 43.05 & 44.44 & 1.33 \\
MCF7 & & & 2.90 \\
Control & 88.04 & 3.10 & 7.52 & 0.95 \\
TAM 6 $\mu \mathrm{g} / \mathrm{ml}$ & 83.05 & 7.16 & 6.89 & 3.80 \\
NFV 6 $\mu \mathrm{g} / \mathrm{ml}$ & 92.80 & 2.46 & 19.48 & 2.21 \\
TAM/NFV & 63.68 & 14.63 & & \\
\hline
\end{tabular}

The relative cell distributions among the quadrants shown in Figure 2 were analysed using the BectonDickinson CellQuest software. LL, lower left (unstained; viable); UL, upper left (annexin-positive; apoptotic); UR, upper right (annexin-positive and propidium iodide-positive; apoptotic/necrotic); LR, lower right (propidium iodide permeable; necrotic); TAM, tamoxifen; NFV, nelfinavir.

tamoxifen alone or in combination were subjected to western blot analysis (Figure 5). Tamoxifen enhanced upregulation of BiP in T47 D and MCF7 cells, and to a lesser in MDA-MB-435 and MDA-MB-453 cells (Figure 5). In MDA-MB-453 cells, expression of the autophagy marker light chain 3B was strongly enhanced. Tamoxifen, nelfinavir, and its combination had no effect on AKT or ERK phosphorylation in T47 D and MCF7 cells but, in MDA-MB-435 and MDA-MB-453 cells, the combination of tamoxifen with nelfinavir markedly enhanced AKT phosphorylation (Figure 5).

\section{Nelfinavir reduces glutathione levels in breast cancer cells}

Tamoxifen has been reported to induce oxidative stress [6]. Oxidative stress is reflected by or can be facilitated by reduced intracellular glutathione levels, because glutathione serves as an endogenous antioxidant and reduced glutathione levels facilitate apoptosis [27]. When breast cancer cells were incubated with tamoxifen or nelfinavir, we observed that nelfinavir reduced glutathione levels in breast cancer cells even more than tamoxifen did (Figure $6 a)$. At a concentration of $6 \mu \mathrm{g} / \mathrm{ml}$, nelfinavir reduced the intracellular glutathione level of MCF7 and MDA-MB435 cells by $21.6 \%$ and $16.6 \%$, respectively $(P<0.05)$. A slight but statistically significant reduction of the glutathione level by $7 \%(P<0.05)$ could be observed for MCF7 cells treated with $6 \mu \mathrm{g} / \mathrm{ml}$ tamoxifen (Figure 6a). The combination of $6 \mu \mathrm{g} / \mathrm{ml}$ nelfinavir with $6 \mu \mathrm{g} / \mathrm{ml}$ tamoxifen, however, did not further reduce the glutathione levels in breast cancer cells in a significant manner (Figure $6 \mathrm{a})$. Since the subtoxic concentration of $6 \mu \mathrm{g} / \mathrm{ml}$ nelfinavir was already effective in reducing intracellular glutathione levels, we tested the effect of nelfinavir at higher concen- trations $(20 \mu \mathrm{g} / \mathrm{ml})$; these higher levels proved to be toxic to all of the four breast cancer cell lines investigated. Figure $6 \mathrm{~b}$ shows that $20 \mu \mathrm{g} / \mathrm{ml}$ nelfinavir reduced intracellular glutathione levels by up to $32.4 \%$ in MCF7 cells and by $30.1 \%$ in MDA-MB-435 cells.

The intracellular glutathione levels might vary not only because of external drug applications, but likewise due to differences in cell growth, nutrient concentrations (especially that of cysteine), and the redox state within the cells or of the surrounding medium. These factors can vary under cell culture conditions. Exogenously applied glutathione or cysteine derivatives such as $\mathrm{N}$-acetyl-cysteine can enhance or replenish intracellular glutathione levels or support the antioxidative effect of glutathione. To analyse the involvement of glutathione depletion on nelfinavir-induced apoptosis, intracellular glutathione contents were replenished by the addition of externally applied glutathione or $N$-acetyl-cysteine. Figure 6c demonstrates that the addition of glutathione, and even more so the addition of $\mathrm{N}$-acetyl-cysteine, can attenuate the cytotoxic effect of nelfinavir on breast cancer cells. In the absence of external glutathione or $\mathrm{N}$-acetyl-cysteine, only $5 \%$ of the MCF7 cells and 12\% of the MDA-MB-435 cells survived the application of $15 \mu \mathrm{g} / \mathrm{ml}$ nelfinavir (Figure $6 \mathrm{c})$. Although the addition of $5 \mathrm{mM}$ glutathione was not without negative effects on the cell viability of MCF7 cells (Figure 6c), the presence of external glutathione enhanced the remaining cell viability of MCF7 cells to $15 \%$ and to $17 \%$ in the case of MDA-MB-435 cells (Figure 6c). In the presence of $5 \mathrm{mM} \mathrm{N}$-acetyl-cysteine, $18 \%$ of the MCF7 cells remained viable, and up to $34 \%$ of the MDA-MB-435 cells survived the addition of nelfinavir (Figure 6c). 


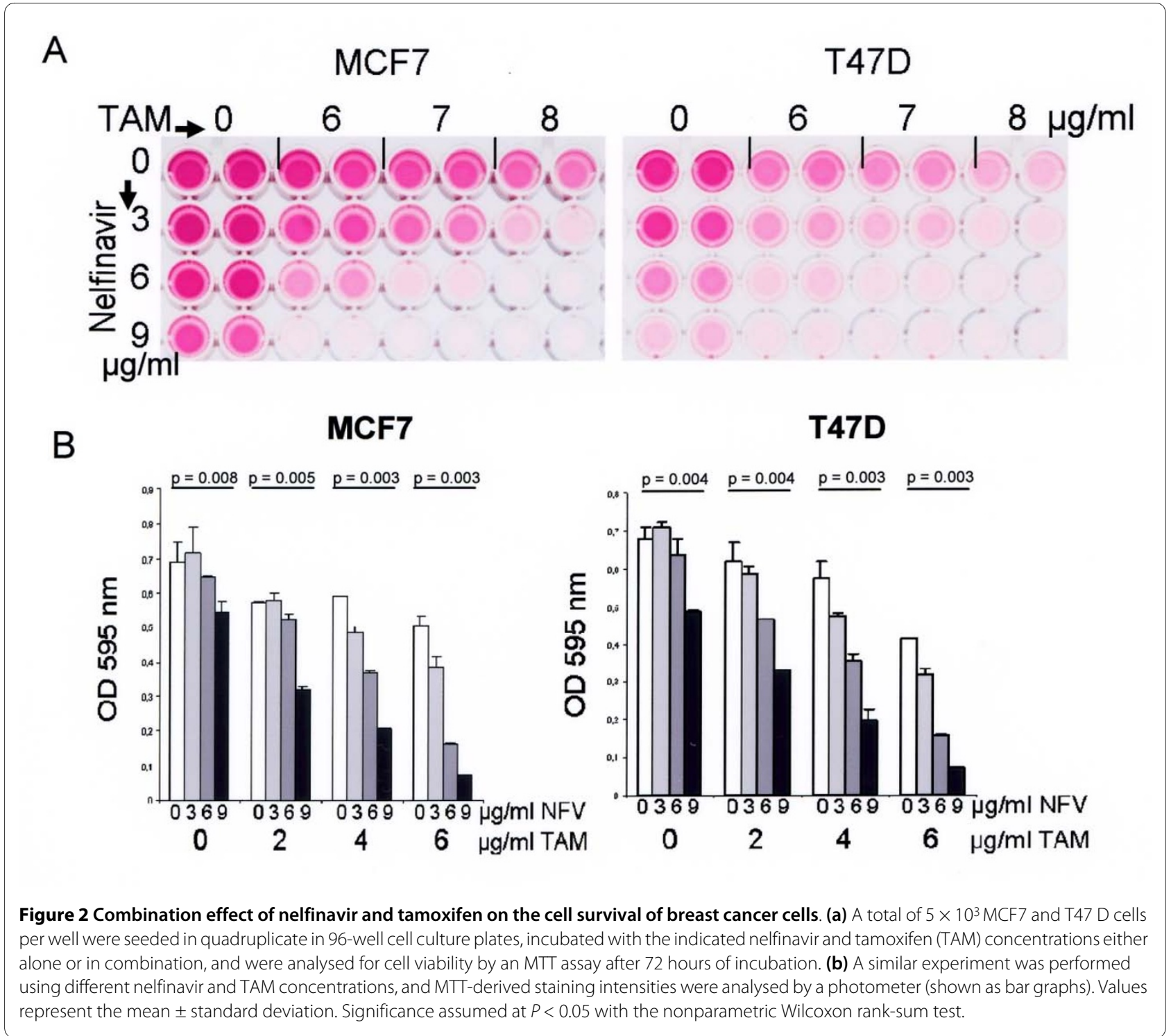

\section{Nelfinavir has no effect on the chymotrypsin-like proteasome activity of breast cancer cells}

Some previous studies have indicated the inhibition of proteasomal activity by HIV protease inhibitors, including nelfinavir [26,28]. The fact that nelfinavir has no influence on expression of the proteasome-regulated NF$\kappa \mathrm{B}$ inhibitor I $\mathrm{B}$ (Figure 4), however, indirectly suggests that nelfinavir has no effect on the proteasomal activity of breast cancer cells.

To clearly detect any influence of nelfinavir on proteasomal activity in breast cancer cells, a direct, bioluminescent proteasome assay was performed. Bortezomib, a specific proteasome inhibitor clinically approved for the treatment of multiple myeloma, was used as a positive control. Figure 7 shows that nelfinavir exerts no significant effect on the chymotryptic proteasome activity in MCF7 and MDA-MB-453 breast cancer cells. The effect of bortezomib on the tested breast cancer cells was likewise poor, however, and $15 \mathrm{ng} / \mathrm{ml}$ bortezomib reduced the chymotrypsin-like activity of the proteasome in MCF7 cells by $37.5 \%$ and in T47 D cells by $17.9 \%$ only (Figure 7). Under these conditions, but at even lower bortezomib concentrations $(4.5 \mathrm{ng} / \mathrm{ml})$, a marked $89.6 \%$ loss in cell viability could be observed in IM9 cells, a bortezomib-sensitive lymphoblastoid cell line. Still, even in IM9 cells, nelfinavir displayed no significant effect on the chymotrypsin-like proteasome activity (Figure 7).

\section{Discussion}

The HIV protease inhibitor nelfinavir is a prospective new anti-cancer drug, as shown by several in vitro as well as in vivo studies [8-13]. The concentrations of nelfinavir needed to induce cell death of cancer cells are higher than those applied for HIV-infected individuals for HIV sup- 

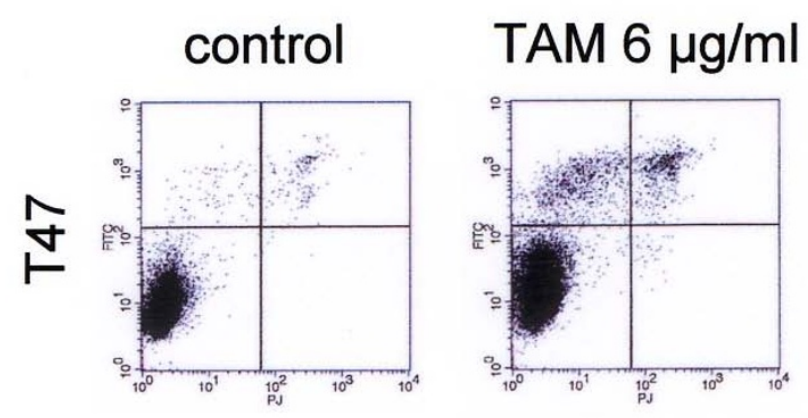

NFV $6 \mu \mathrm{g} / \mathrm{ml}$
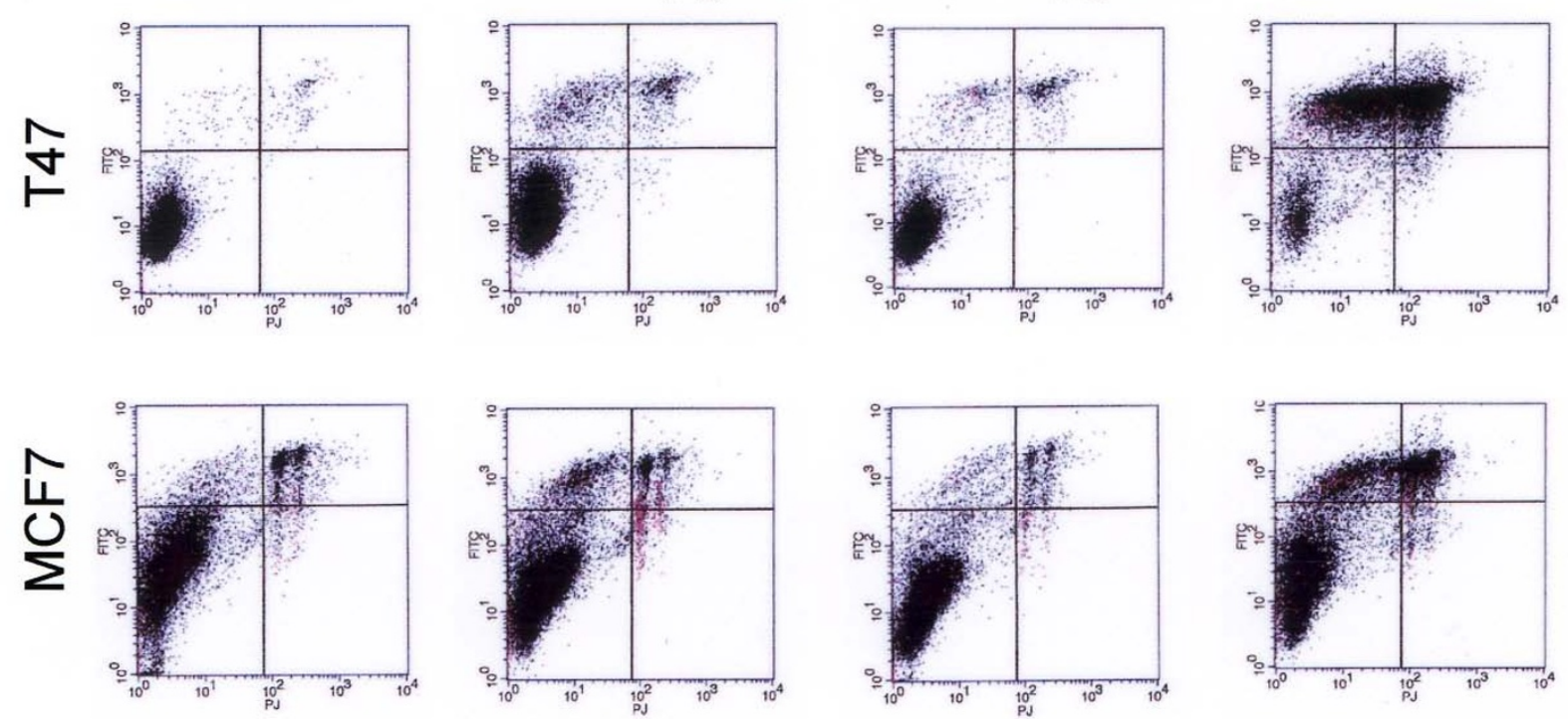

TAM/NFV

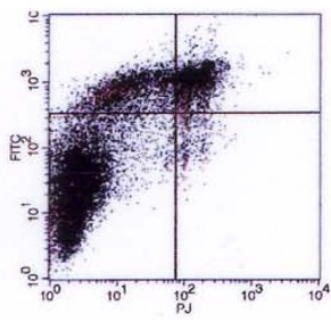

Figure 3 Combination of nelfinavir and tamoxifen enhances apoptosis in breast cancer cells. The breast cancer cell lines MCF7 and T47 D were incubated with the indicated nelfinavir (NFV) and tamoxifen (TAM) concentrations either alone at $6 \mu \mathrm{g} / \mathrm{ml}$ or in combination $(6 \mu \mathrm{g} / \mathrm{ml} \mathrm{NFV} \mathrm{plus} 6 \mu \mathrm{g} /$ $\mathrm{mlTAM}$ ), and after 48 hours of incubation were analysed by FACScan analysis for the occurrence of apoptosis (FITC-annexin binding) and necrosis (propidium iodide permeability). FL-1 setting (propidium iodide; PJ), $575 \mathrm{~nm}$; FL-2 setting (FITC), $530 \mathrm{~nm}$.

pression, but this may be achieved by the application of higher oral or intravenous doses of nelfinavir [25]. Still, the prospects of nelfinavir as an anti-cancer drug will rely less on its efficacy as a single drug and more on its ability to cooperate with or sensitise to other chemotherapeutic drugs or cancer treatment options. For example, we have recently demonstrated that nelfinavir cooperates with the multiple kinase inhibitor sorafenib to induce apoptosis in various cancer cell types [26,29], and enhances TNFrelated apoptosis inducing ligand sensitivity in ovarian cancer cells [30].

The present results show that the cytotoxic effects of nelfinavir on breast cancer cells can be enhanced by combination with tamoxifen, thus allowing the effective concentration of nelfinavir to be reduced. Tamoxifen, although originally designed and applied as a selective oestrogen receptor modulator, also represents a drug with several described pleiotropic anti-tumoral effects $[6,7]$ - and two recent and independent studies observed that tamoxifen is able to induce the endoplasmic reticulum stress reaction $[31,32]$, thus explaining the synergistic effect of nelfinavir and tamoxifen on the induction of endoplasmic reticulum stress. The nelfinavir-boosting effect of tamoxifen was obviously independent of its ability to induce oxidative stress [6]. Instead, we observed that nelfinavir itself reduced cellular glutathione levels, indicating the occurrence of oxidative stress after nelfina- vir treatment. Induction of oxidative stress occurs within a few hours as an early effect of nelfinavir treatment and has so far been neglected as an additional mechanism of the pleiotropic anti-cancer effects of nelfinavir. The observation that the effect of nelfinavir can be attenuated by the addition of antioxidants (glutathione or $\mathrm{N}$-acetylcysteine) could have an impact on the efficacy of nelfinavir in cancer cells, as well as on the nelfinavir-induced adverse effects occurring in HIV-infected persons.

Nelfinavir has been reported to exert a radiosensitising effect by inhibiting proteasome activity and AKT signalling [16]. Inhibition of proteasomal activity or AKT signalling in breast cancer cells, however, was not observed in the present study. In contrast, nelfinavir markedly enhanced AKT phosphorylation in some breast cancer cell lines (MDA-MB-453 cells and MDA-MB-435 cells). This observation is not surprising, however, since we previously demonstrated activation of the cell-protective ERK1/2 signalling pathway by nelfinavir [26]. The endoplasmic stress reaction is primarily a cell-protective mechanism, aiming to rescue cells from transient stressinduced cell damage [21,33]. Longer exposure to cell stress mechanisms or a cellular inability to cope with the stress-induced cell damage then finally induces a switch from cell protection to autophagy and apoptosis [21,33]. Endoplasmic reticulum stress has repeatedly been shown to induce activation of both ERK1/2 and AKT signalling 


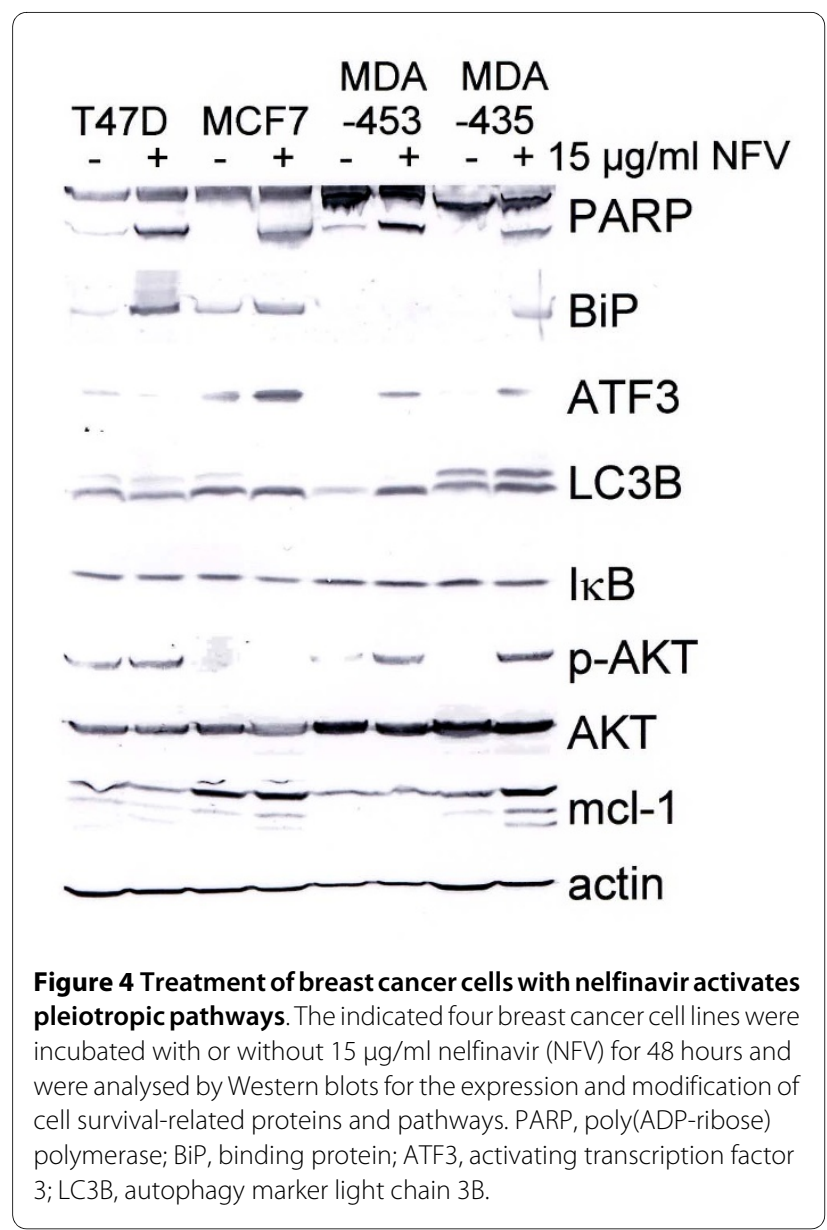

[34-37]. Several studies, however, have likewise shown that AKT activation, which can occur directly at the endoplasmic reticulum [38], primarily represents a shortterm effect, and prolonged exposure of cells to endoplasmic reticulum stress indeed induces AKT inactivation $[38,39]$. In fact, we observed a reduced AKT phosphorylation when breast cancer cells were treated with nelfinavir for more than 48 hours (data not shown), although this indicates downregulation of AKT phosphorylation as a secondary event. The present data therefore do not exclude the potential use of nelfinavir as a radiosensitiser even for breast cancer patients, but a potential negative interaction between these two treatment options, especially shortly after nelfinavir application, should be kept in mind.

In addition to the data on AKT signalling, the present data revealed some other differences to previous studies performed by us and other workers on different cancer cell types. For example, upregulation of the anti-apoptotic mcl-1 protein by nelfinavir - as we observed in ovarian cancer cells [26] and leukaemia cells [29] - could only be observed in a single breast cancer cell line (MDA-MB435 cells), and only at high concentrations of nelfinavir

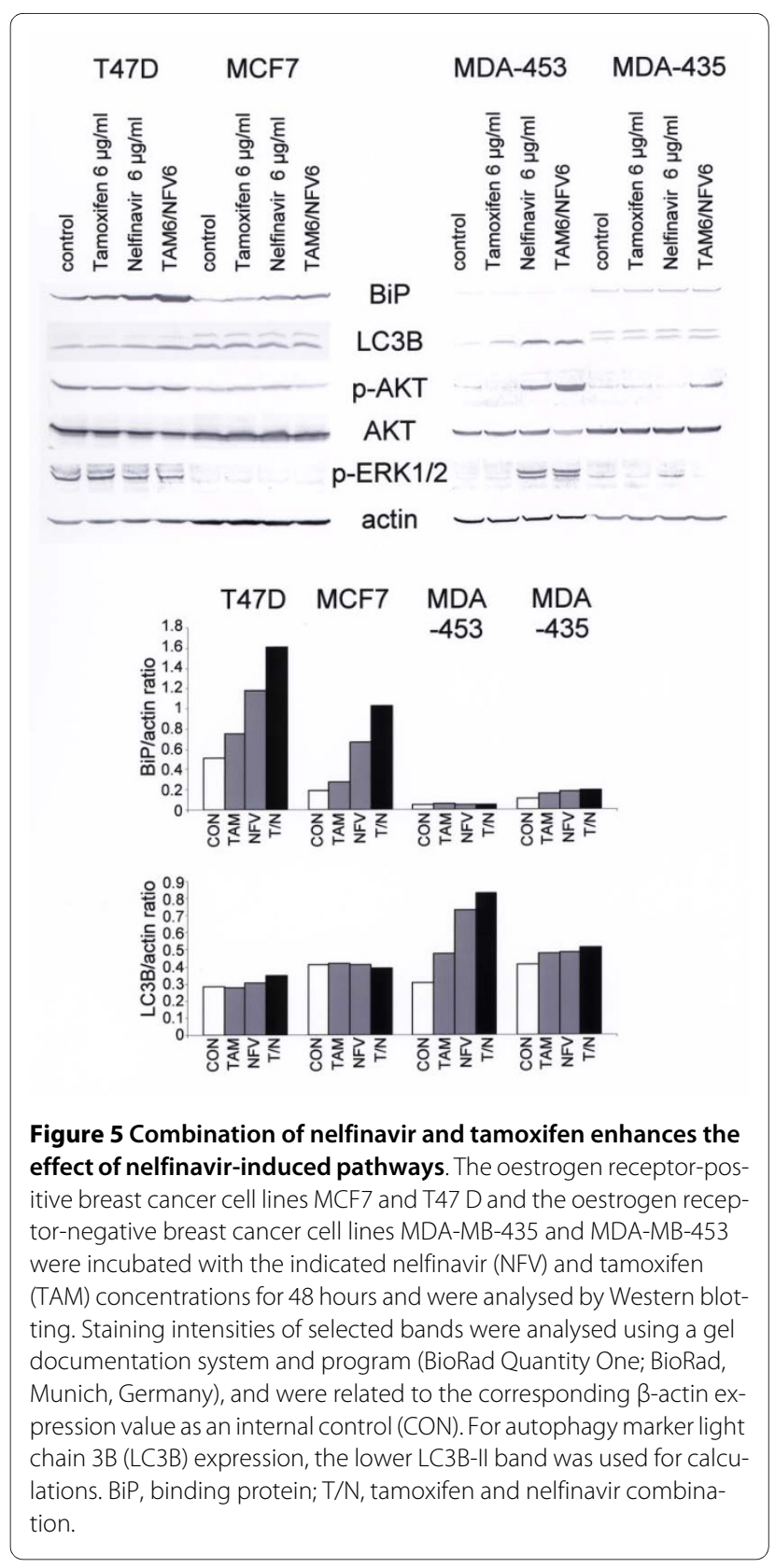

(Figure 4). Further, we could not demonstrate proteasome inhibition by nelfinavir in breast cancer cells.

Although nelfinavir induced cell death in all four breast cancer cell lines tested, the data presented further indicate that the cell lines respond quite differently to nelfinavir, especially regarding the effect on cell stress, autophagy, and apoptosis. This variation might be due to the different hormone receptor status of the cells, but likewise may be due to the different malignancies of the tumours from which these cell lines have been derived. We therefore tried to include various types of breast cancer cell lines in the present study, ranging from hormone receptor-positive breast cancer cells of a high differentia- 

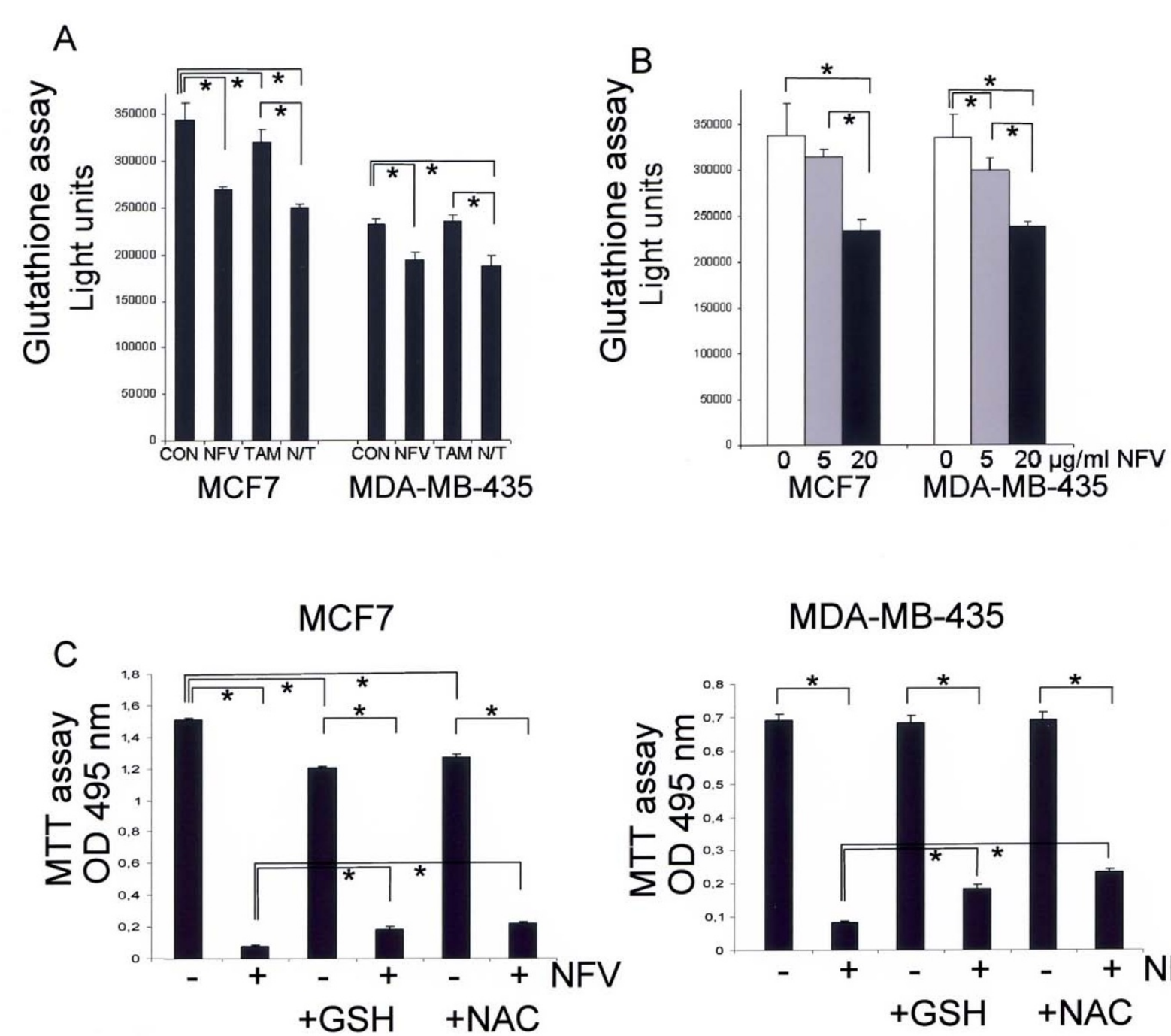

Figure 6 Nelfinavir, but not tamoxifen, induces glutathione reduction in breast cancer cells. (a) A total of $5 \times 10^{3}$ MCF7 and MDA-MB-435 cells per well were seeded in 96-well cell culture dishes and were incubated for 5 hours with either $6 \mu \mathrm{g} / \mathrm{ml}$ nelfinavir (NFV) or $6 \mu \mathrm{g} / \mathrm{ml}$ tamoxifen (TAM) alone or in combination (N/T). Intracellular glutathione levels were quantified using the bioluminescent Promega GSH-Glo ${ }^{\text {TM }}$ glutathione assay (Promega, Mannheim, Germany). (b) MCF7 and MDA-MB-435 cells were incubated for 5 hours with the indicated NFV concentrations and were analysed for the cellular glutathione level as described in (a). (c) MCF7 and MDA-MB-435 cells were incubated with or without $15 \mu \mathrm{g} / \mathrm{ml} \mathrm{NFV} \mathrm{for} 72 \mathrm{hours}$ in the presence or absence of $5 \mathrm{mM}$ glutathione (GSH) or $5 \mathrm{mM} \mathrm{N}$-acetyl-cysteine (NAC), and were analysed for cell survival by an MTT assay. Values represent the mean \pm standard deviation. ${ }^{*}$ Significance assumed at $P<0.05$ with the nonparametric Mann-Whitney $\cup$ rank-sum test. CON, control.

tion grade ( $\mathrm{T} 47 \mathrm{D}$ cells) to highly de-differentiated hormone receptor-negative breast cancer cells (MDA-MB435 cells). Interestingly, especially when low doses of nelfinavir were applied, the de-differentiated hormone receptor-negative breast cancer cell lines (MDA-MB-453 and MDA-MB-435 cells) appeared to react even better to nelfinavir than the T47 D and MCF7 cells (Figure 1).

We observed that the combination of tamoxifen and nelfinavir was able to induce cell death in oestrogen receptor-positive as well as in oestrogen receptor-negative breast cancer cell lines. This indicates that both oestrogen receptor-positive as well as oestrogen recep- tor-negative breast cancer patients could benefit from a combination of these two drugs.

Since both nelfinavir and tamoxifen have to be used at concentrations higher than those used to inhibit the HIV protease in HIV-infected persons or the oestrogen receptor in hormone receptor-positive breast cancer patients, however, care has to be taken that no unexpected adverse effects occur - especially when both drugs, although displaying moderate and tolerable adverse effects as single agents, are combined. Further, the observed reduction in glutathione levels by nelfinavir might cause an unexpected drug sensitisation in other tissues. 

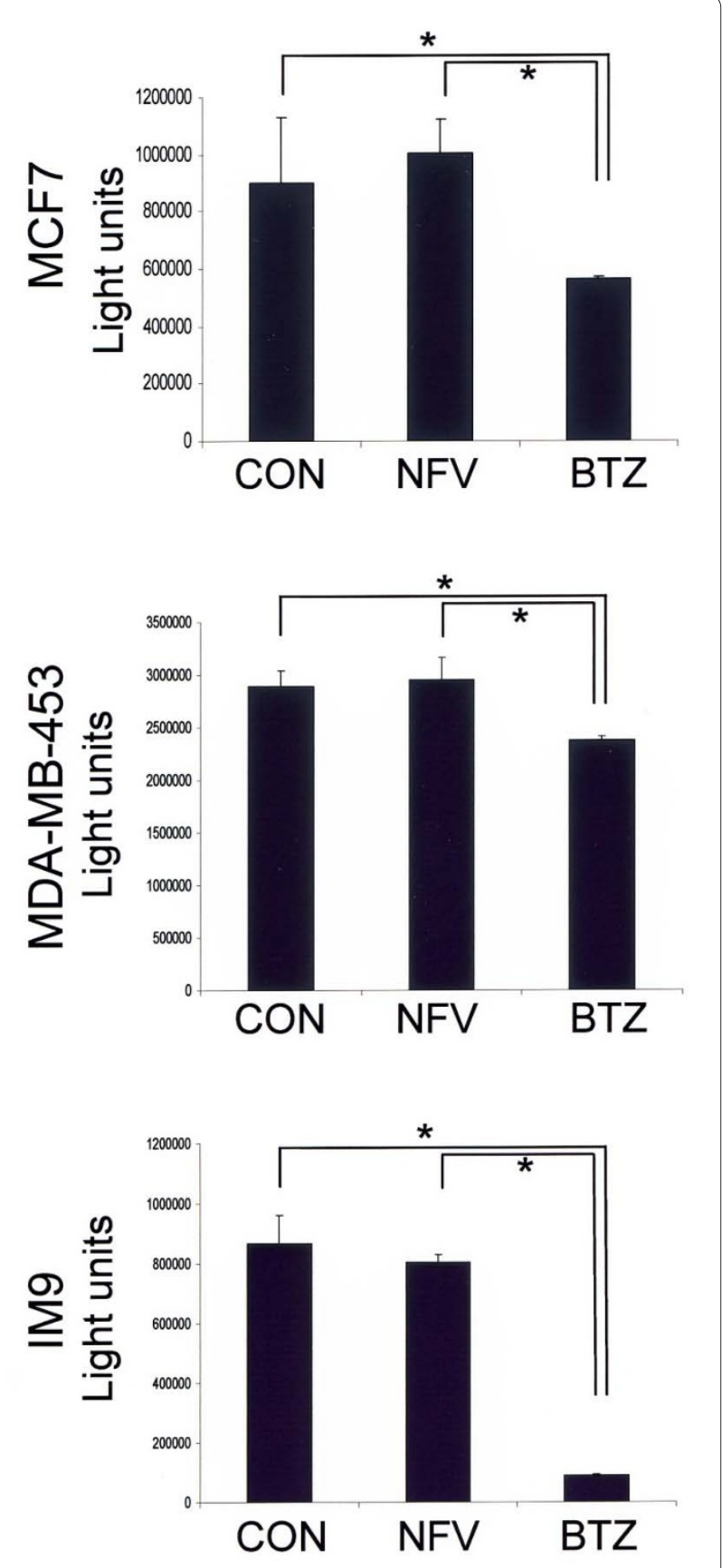

Figure 7 Nelfinavir has no effect on the chymotrypsin-like proteasome activity of breast cancer cells. A total of $5 \times 10^{3}$ MCF7 and MDA-MB-435 cells per well were seeded in quadruplicate in 96-well cell culture dishes and were incubated for 5 hours with either $15 \mu \mathrm{g} /$ $\mathrm{ml}$ nelfinavir (NFV) or $15 \mathrm{ng} / \mathrm{ml}$ bortezomib (BTZ). Chymotryptic proteasomal activity was analysed using the bioluminescent Promega Proteasome-Glo ${ }^{\text {TM }}$ assay (Promega, Mannheim, Germany) with SucLLVY-aminoluciferin as a substrate. The BTZ-sensitive myeloic leukaemia cell line IM9 was used as a BTZ-responsive control and was treated with $8 \mu \mathrm{g} / \mathrm{ml} \mathrm{NFV}$ and $4.5 \mathrm{ng} / \mathrm{ml}$ BTZ. Values represent the mean \pm standard deviation. ${ }^{*}$ Significance assumed at $P<0.05$ with the nonparametric Mann-Whitney U rank-sum test. CON, control.
Clinical studies on breast cancer patients testing the described combination of nelfinavir and tamoxifen are thus of high interest in order to assess both efficacy and safety of this drug combination.

\section{Conclusions}

The present study demonstrates the efficacy of nelfinavir in breast cancer cells as a single agent, and a possible combination treatment with tamoxifen. Both nelfinavir and tamoxifen are already-approved drugs with known pharmacokinetics, and they generally exhibit relative mild and well tolerable adverse effects even after longterm application. Since the concentrations of both drugs have to be increased for an efficient cancer therapy, and a combination of these two drugs has not yet been tested in humans, however, it is important to first test the safety and tolerability of this combination in phase I studies.

\section{Abbreviations}

ATF3: activating transcription factor 3; BiP: binding protein; ELISA: enzymelinked immunosorbent assay; ERK: extracellular signal-regulated kinase: FACS: fluorescence-activated cell sorting; FITC: fluorescein isothiocyanate; MTT: 3(4,5-dimethylthiazol-2-yl)-2,5-diphenyltetrazolium bromide; NF: nuclear factor; PBS: phosphate-buffered saline; TNF: tumour necrosis factor.

\section{Competing interests}

The authors declare that they have no competing interests.

\section{Authors' contributions}

$\mathrm{ABr}$ designed and coordinated the experiments, $\mathrm{KF}$ and $\mathrm{ABu}$ helped to draft the manuscript, and IM helped to draft the manuscript and performed the statistical analysis. All authors read and approved the final manuscript.

\section{Acknowledgements}

The authors are greatly indebted to Marianne Vogel, Reinhild Joswig, and Petra Burger for their excellent and highly motivated technical assistance. The generous supply of nelfinavir by Pfizer (Groton, CT, USA) is gratefully appreciated. This work was supported by the German Research Foundation (Deutsche Forschungsgemeinschaft DFG BR 3641/1-1 and DFG BR 3641/3-1).

\section{Author Details}

1Department of Obstetrics and Gynaecology, Campus Innenstadt, LudwigMaximilians-University Munich, 11 Maistrasse, Munich 80337, Germany and 2Department of Obstetrics and Gynaecology, Campus Grosshadern, LudwigMaximilians-University Munich, 15 Marchioninistrasse, Munich 81377, Germany

Received: 1 March 2010 Revised: 31 May 2010

Accepted: 1 July 2010 Published: 1 July 2010

\section{References}

1. Jemal A, Siegel R, Ward E, Hao Y, Xu J, Thun MJ: Cancer statistics, 2009. CA Cancer J Clin 2009, 59:225-249.

2. Goldhirsch A, Ingle JN, Gelber RD, Coates AS, Thurlimann B, Senn HJ: Thresholds for therapies: highlights of the St Gallen International Expert Consensus on the primary therapy of early breast cancer 2009. Ann Oncol 2009, 20:1319-1329.

3. Fisher B, Redmond C: Systemic therapy in node-negative patients: updated findings from NSABP clinical trials. National Surgical Adjuvant Breast and Bowel Project. J Nat/ Cancer Inst Monogr 1992, 11:105-116.

4. Howell A: The endocrine prevention of breast cancer. Best Pract Res Clin Endocrinol Metab 2008, 22:615-623

5. Harichand-Herdt S, Zelnak A, O'Regan R: Endocrine therapy for the treatment of postmenopausal women with breast cancer. Expert Rev Anticancer Ther 2009, 9:187-198. 
6. Gundimeda U, Chen ZH, Gopalakrishna R: Tamoxifen modulates protein kinase $C$ via oxidative stress in estrogen receptor-negative breast cancer cells. J Biol Chem 1996, 271:13504-13514.

7. Mandlekar S, Kong AN: Mechanisms of tamoxifen-induced apoptosis. Apoptosis 2001, 6:469-477.

8. Pore N, Gupta AK, Cerniglia GJ, Maity A: HIV protease inhibitors decrease VEGF/HIF-1a expression and angiogenesis in glioblastoma cells. Neoplasia 2006, 8:889-895

9. Gills JJ, Lopiccolo J, Tsurutani J, Shoemaker RH, Best CJ, Abu-Asab MS, Borojerdi J, Warfel NA, Gardner ER, Danish M, Hollander MC, Kawabata S, Tsokos M, Figg WD, Steeg PS, Dennis PA: Nelfinavir, A lead HIV protease inhibitor, is a broad-spectrum, anticancer agent that induces endoplasmic reticulum stress, autophagy, and apoptosis in vitro and in vivo. Clin Cancer Res 2007, 13:5183-5194.

10. Cohen J: Biomedicine. HIV drug shows promise as potential cancer treatment. Science 2007, 317:1305.

11. Plastaras JP, Vapiwala N, Ahmed MS, Gudonis D, Cerniglia GJ, Feldman MD, Frank I, Gupta AK: Validation and toxicity of PI3K/Akt pathway inhibition by HIV protease inhibitors in humans. Cancer Biol Ther 2008 , 7:628-635.

12. Brunner TB, Geiger M, Grabenbauer GG, Lang-Welzenbach M, Mantoni TS, Cavallaro A, Sauer R, Hohenberger W, McKenna WG: Phase I trial of the human immunodeficiency virus protease inhibitor nelfinavir and chemoradiation for locally advanced pancreatic cancer. J Clin Oncol 2008, 26:2699-2706.

13. Chow WA, Jiang C, Guan M: Anti-HIV drugs for cancer therapeutics: back to the future? Lancet Oncol 2009, 10:61-71.

14. Pyrko P, Kardosh A, Wang W, Xiong W, Schonthal AH, Chen TC: HIV-1 protease inhibitors nelfinavir and atazanavir induce malignant glioma death by triggering endoplasmic reticulum stress. Cancer Res 2007, 67:10920-10928.

15. Bruning A, Burger P, Vogel M, Rahmeh M, Gingelmaiers A, Friese $K$, Lenhard M, Burges A: Nelfinavir induces the unfolded protein response in ovarian cancer cells, resulting in ER vacuolization, cell cycle retardation and apoptosis. Cancer Biol Ther 2009, 8:226-232.

16. Gupta AK, Li B, Cerniglia GJ, Ahmed MS, Hahn SM, Maity A: The HIV protease inhibitor nelfinavir downregulates Akt phosphorylation by inhibiting proteasomal activity and inducing the unfolded protein response. Neoplasia 2007, 9:271-278.

17. Bertolotti A, Zhang Y, Hendershot LM, Harding HP, Ron D: Dynamic interaction of BiP and ER stress transducers in the unfolded-protein response. Nat Cell Biol 2000, 2:326-332.

18. Lee AS: The ER chaperone and signaling regulator GRP78/BiP as a monitor of endoplasmic reticulum stress. Methods 2005, 35:373-381.

19. Fribley $A$, Wang CY: Proteasome inhibitor induces apoptosis through induction of endoplasmic reticulum stress. Cancer Biol Ther 2006, 5:745-748.

20. Fels DR, Koumenis $C$ : The PERK/elF2a/ATF4 module of the UPR in hypoxia resistance and tumor growth. Cancer Biol Ther 2006, 5:723-728.

21. Lin JH, Li H, Yasumura D, Cohen HR, Zhang C, Panning B, Shokat KM, Lavail $M M$, Walter $P$ : IRE1 signaling affects cell fate during the unfolded protein response. Science 2007, 318:944-949.

22. Boelens J, Lust S, Offner F, Bracke ME, Vanhoecke BW: Review. The endoplasmic reticulum: a target for new anticancer drugs. In Vivo 2007, 21:215-226.

23. Regazzi MB, Villani P, Maserati R, Seminari E, Pan A, LoCaputo F, Gambarana E, Fiocchi C: Clinical pharmacokinetics of nelfinavir combined with efavirenz and stavudine during rescue treatment of heavily pretreated HIV-infected patients. J Antimicrob Chemother 2000 45:343-347.

24. Regazzi MB, Seminari E, Villani P, Carriero PL, Montagna M, Marubbi F, Maserati R: Nelfinavir suspension obtained from nelfinavir tablets has equivalent pharmacokinetic profile. J Chemother 2001, 13:569-574.

25. Kaldor SW, Kalish VJ, Davies JF, Shetty BV, Fritz JE, Appelt K, Burgess JA, Campanale KM, Chirgadze NY, Clawson DK, Dressman BA, Hatch SD, Khalil DA, Kosa MB, Lubbehusen PP, Muesing MA, Patick AK, Reich SH, Su KS, Tatlock JH: Viracept (nelfinavir mesylate, AG1343): a potent, orally bioavailable inhibitor of HIV-1 protease. J Med Chem 1997, 40:3979-3985.

26. Bruning A, Burger P, Vogel M, Gingelmaier A, Friese $K$, Burges A: Nelfinavir induces mitochondria protection by ERK1/2-mediated mcl-1 stabilization that can be overcome by sorafenib. Invest New Drugs 2009 in press.

27. Franco R, Cidlowski JA: Apoptosis and glutathione: beyond an antioxidant. Cell Death Differ 2009, 16:1303-1314.

28. Schmidtke G, Holzhutter HG, Bogyo M, Kairies N, Groll M, de Giuli R, Emch S, Groettrup M: How an inhibitor of the HIV-I protease modulates proteasome activity. J Biol Chem 1999, 274:35734-35740.

29. Bruning A, Rahmeh M, Gingelmaier A, Friese K: The mitochondriaindependent cytotoxic effect of nelfinavir on leukemia cells can be enhanced by sorafenib-mediated $\mathrm{mcl}-1$ downregulation and mitochondrial membrane destabilization. Mol Cancer 2010, 9:19.

30. Bruning A, Vogel M, Burger P, Rahmeh M, Gingelmaier A, Friese K, Lenhard $M$, Burges A: Nelfinavir induces TRAIL receptor upregulation in ovarian cancer cells. Biochem Biophys Res Commun 2008, 377:1309-1314.

31. Scriven P, Coulson S, Haines R, Balasubramanian S, Cross S, Wyld L: Activation and clinical significance of the unfolded protein response in breast cancer. Br J Cancer 2009, 101:1692-1698.

32. Andersson H, Helmestam M, Zebrowska A, Olovsson M, Brittebo E: Tamoxifen-induced adduct formation and cell stress in human endometrial glands. Drug Metab Dispos 2010, 38:200-207.

33. Wek RC, Jiang HY, Anthony TG: Coping with stress: elF2 kinases and translational control. Biochem Soc Trans 2006, 34:7-11.

34. Hu P, Han Z, Couvillon AD, Exton JH: Critical role of endogenous Akt/ IAPs and MEK $1 / E R K$ pathways in counteracting endoplasmic reticulum stress-induced cell death. J Biol Chem 2004, 279:49420-49429.

35. Matthews JA, Belof JL, Acevedo-Duncan M, Potter RL: Glucosamineinduced increase in Akt phosphorylation corresponds to increased endoplasmic reticulum stress in astroglial cells. Mol Cell Biochem 2007, 298:109-123.

36. Jiang CC, Yang F, Thorne RF, Zhu BK, Hersey P, Zhang XD: Human melanoma cells under endoplasmic reticulum stress acquire resistance to microtubule-targeting drugs through XBP-1-mediated activation of Akt. Neoplasia 2009, 11:436-447.

37. Price J, Zaidi AK, Bohensky J, Srinivas V, Shapiro IM, Ali H: Akt-1 mediates survival of chondrocytes from endoplasmic reticulum-induced stress. J Cell Physiol 2010, 222:502-508.

38. Hosoi T, Hyoda K, Okuma Y, Nomura Y, Ozawa K: Akt up- and downregulation in response to endoplasmic reticulum stress. Brain Res 2007, 1152:27-31.

39. Dai R, Chen R, Li H: Cross-talk between PI3K/Akt and MEK/ERK pathways mediates endoplasmic reticulum stress-induced cell cycle progression and cell death in human hepatocellular carcinoma cells. Int J Oncol 2009, 34:1749-1757.

doi: $10.1186 /$ bcr2602

Cite this article as: Brüning et al., Tamoxifen enhances the cytotoxic effects of nelfinavir in breast cancer cells Breast Cancer Research 2010, 12:R45

\section{Submit your next manuscript to BioMed Central and take full advantage of:}

- Convenient online submission

- Thorough peer review

- No space constraints or color figure charges

- Immediate publication on acceptance

- Inclusion in PubMed, CAS, Scopus and Google Scholar

- Research which is freely available for redistribution 